\title{
Characteristics and Mechanism of Action of a Heat-Stable Enterotoxin Produced by Klebsiella pneumoniae from Infants with Secretory Diarrhea
}

\author{
ALFREDO GUARINO, STEFANO GUANDALINI, MARIA ALESSIO, FABRIZIO GENTILE, \\ LUIGI TARALLO, GUGLIELMO CAPANO, MAURIZIO MIGLIAVACCA, AND ARMIDO RUBINO
}

Department of Pediatrics, University of Naples, Naples, Italy

\begin{abstract}
Escherichia coli heat-stable enterotoxins (ST) are classified into STa and STb according to their physicochemical and biologic characteristics. STa induces diarrhea, activating the guanylate cyclase-cGMP system. ST-like enterotoxins can be produced by bacteria other than $E$. coli, including Klebsiella pneumoniae. A Klebsiella ST has previously been shown to share some chemical and immunologic characteristics with $E$. coli $\mathrm{ST}$. Aiming to define better the nature of Klebsiella ST, we have screened 237 children with diarrhea and 179 controls for ST-producing Klebsiella, using the SMA. We detected 26 Klebsiella strains from patients, two of which were positive in the SMA, and 36 from controls, all negative for ST. A partial purification was performed using an acetone precipitation followed by ultrafiltration and gel filtration techniques. Klebsiella toxin was heat-stable, methanol-soluble, sensitive to mercaptoethanol, active at acid $\mathrm{pH}$ values, but not at $\mathbf{p H}>8$. The time course of Klebsiella toxin in the SMA resembled that of $E$. coli STa. Klebsiella ST caused reduced $\mathrm{Na}$ absorption and net $\mathrm{Cl}$ secretion in rabbit ileal mucosa mounted in Ussing chambers. It was found to increase the cGMP but not the cAMP concentration. Finally, Klebsiella ST did not react with anti-E. coli STa MAb in a competitive ELISA. We conclude that $K$. pneumoniae may induce diarrhea through the production of an STa similar but not identical to $E$. coli STa. (Pediatr Res 25:514-518, 1989)
\end{abstract}

\section{Abbreviations}

ST, heat-stable enterotoxin GW/BW ratio, gut wt/body wt ratio Isc, intensity of short circuit current m-s/s-m, mucosa-serosa/serosa mucosa $\mathrm{Ji}_{(\mathrm{m}-\mathrm{s})}$, ion flux mucosa-serosa $\mathrm{J}$, residual ion flux SMA, suckling mouse assay

ST-producing Escherichia coli are among the most common agents of diarrhea in developing countries (1) but have been detected in industrialized countries as well (2). The pathophysiology of the diarrhea induced by ST has been extensively investigated. It is the result of a multistep process involving the binding of the toxin to receptors located on the brush border $(3,4)$, the activation of the guanylate cyclase-cGMP system (5), and the induction of anion and water secretion (6).

Received August 1, 1988; accepted December 14, 1988.

Correspondance, proofs, and reprint requests Alfredo Guarino, Department of Pediatrics, University of Naples, Via S. Pansini, 5, 80131 Naples, Italy.
It is now becoming clear that ST enterotoxins are elaborated not only by $E$. coli strains but also by other bacteria. We recently described the physicochemical properties of an E. coli ST-like enterotoxin produced by Citrobacter freundii and found that it cross-reacted with MAb raised against pure $E$. coli ST (7). Klipstein et al. have investigated the biochemical (8) and immunologic (9) properties of an ST produced by Klebsiella pneumoniae and found it similar to the ST produced by $E$. coli.

Aiming to define better the nature and the characteristics of Klebsiella ST, we have systematically searched for Klebsiella in the stools of children with diarrhea. Two SMA-positive strains of $K$. pneumoniae have been isolated from two infants with diarrhea. In this report, we describe our studies of the physicochemical characteristics, the mechanism of action, and the lack of cross-reactivity of $K$. pneumoniae enterotoxic activity with anti-E. coli ST MAb.

\section{MATERIALS AND METHODS}

Patients and controls. Patients were 237 children (mean age 20 mo, range $0-10 \mathrm{y}$ ), admitted to our Unit because of acute (lasting $<14 \mathrm{~d}$ ) diarrhea. Children known to have received antibiotics were excluded from the study. Controls were 179 children matched for age, seen as inpatien's or outpatients, but without gastrointestinal problems.

Isolation and identification of enteric pathogens. In all study subjects, a systematic search for enteric pathogens was made as previously described (7). Isolates were defined as Klebsiella spp. by a multitest system (API $20 \mathrm{E}$, Ayerst Italiana).

Detection and partial purification of enterotoxic activity. ST. production was tested on five different colonies of Klebsiella from each specimen. K. pneumoniae was grown in Casamino acid-yeast extract media for $18 \mathrm{~h}$ at $37^{\circ} \mathrm{C}$ in a shaker incubator. The culture was then centrifuged and the supernatant tested in the SMA according to the method of Giannella (10). A GW/BW ratio $>0.083$ was considered positive. E. coli strain $214 \mathrm{C} 1$, STpositive LT-negative, obtained by Dr. Caprioli (Istituto Superiore di Sanitá, Rome), was used as a positive control for the production of ST.

Preparation of a partially purified extract was performed as described by Klipstein and Engert (8), with minor modifications. Briefly, $K$. pneumoniae strain AL55, isolated from the first patient described under "Case reports" in the "Results," positive in the SMA, was grown in trypticase soy broth for $18 \mathrm{~h}$ at $37^{\circ} \mathrm{C}$ in stationary aerobiosis. The culture was then centrifuged at $35000 \times g$, and the supernatant was filtered through a $0.45-\mu \mathrm{m}$ pore-size membrane and precipitated by the addition of 8 vol of acetone. The precipitate, dried and redissolved in water, was sequentially filtered through ultrafiltration membranes (PM-10 and UM-2; Amicon corp, Lexington, MA). This material was then lyophilized and stored at $-20^{\circ} \mathrm{C}$ until used. Since the 
maximal enterotoxic activity was associated with the UM-2 fraction, this material was subjected to further purification by gel filtration. A 2.5- $\times 80-\mathrm{cm}$ column was packed with Sephadex G-25 Superfine (Pharmacia Fine Chemicals SpA, Milan, Italy) and equilibrated with $0.02-\mathrm{M}$ ammonium bicarbonate, $\mathrm{pH} 7.8$, at $4^{\circ} \mathrm{C}$. The void vol and the salt vol were determined using Dextran Blue 2000 (Pharmacia) and $\mathrm{NaCl}$. Aliquots (100-150 $\mathrm{mg}$ ) of lyophilized material from the UM-2 retentate were redissolved in $2 \mathrm{~mL}$ of the same buffer and eluted from the gel at $4^{\circ} \mathrm{C}$ at $24 \mathrm{~mL} / \mathrm{h}$. Fractions of $5 \mathrm{~mL}$ were collected, monitored by absorbance at $280 \mathrm{~nm}$ for protein content, and every third fraction was assayed for total hexose content by the anthrone reaction, using mannose as the standard. Spectrophotometric measurements were performed by a Hitachi Perkin-Elmer spectrophotometer model 139 (Perkin-Elmer Italiana SpA, Monza, Italy). Since the maximal secretory activity was associated with the void vol, these fractions were pooled, lyophilized, and stored at $-20^{\circ} \mathrm{C}$ until used. Protein concentration was determined by the Lowry method (11).

Physicochemical and biologic characterization. The following characteristics were examined: heat-stability, methanol-solubility, $\mathrm{pH}$ effect, effect of the reducing agents 2-mercaptoethanol and dithiothreitol. The time course of $K$. pneumoniae enterotoxic activity was determined in the SMA. Details of these methods have been described (7).

Immunologic studies. Culture supernatant fluids from $K$. pneumoniae SMA-positive strains were tested using an ELISA method, as described by Thompson et al. (12). We used anti-ST MAb 20C1B8 prepared against ST from E. coli strain 18 D (13) at a final dilution of $1: 160$ of $2 \mu \mathrm{g} / \mathrm{mL}$ stock solution. An 8point standard curve with pure $E$. coli STa $(25-1000 \mathrm{pg} /$ well) was included in each plate. In the ELISA, $5-\mu \mathrm{L}$ of culture supernatant of Klebsiella strains as well as of E. coli $214 \mathrm{Cl}$ were used. Each test was performed in duplicate, but it was repeated five times on SMA-positive Klebsiella strains.

Short circuit current and ion flux measurements. New Zealand white rabbits older than 4 mo were used. Animals were killed by cervical dislocation; a 15-cm segment of distal ileum was taken and sectioned along the mesenteric insertion. After rinsing, the piece was placed in ice-cold Ringer's solution (53- $\mathrm{mM} \mathrm{NaCl}, 5-$ $\mathrm{mM} \mathrm{KCl}, 30.5-\mathrm{mM} \mathrm{Na}_{2} \mathrm{SO}_{4}, 30.5-\mathrm{mM}$ mannitol, $1.69-\mathrm{mM}$ $\mathrm{Na}_{2} \mathrm{PO}_{4}, 0.3-\mathrm{mM} \mathrm{NaHPO}, 1.25-\mathrm{mM} \mathrm{CaCl}_{2}, 1.10-\mathrm{mM} \mathrm{MgCl}$ $25-\mathrm{mM} \mathrm{NaHCO}_{3}$ ), which was constantly bubbled with $95 \% \mathrm{O}_{2}$, $5 \% \mathrm{CO}_{2}$.

The serosal and muscle layers were removed as previously described, and four pieces of stripped ileum were mounted in Ussing chambers (14). Transepithelial electrical potential difference, total electric conductance, and Isc were determined as previously described $(14,15)$. Unidirectional transepithelial fluxes (J) of $\mathrm{Na}$ and $\mathrm{Cl}$ from mucosa to serosa (m-s) and from serosa to mucosa $(\mathrm{s}-\mathrm{m})$ were measured in tissues matched on the basis of total electric conductance under short circuit conditions, using ${ }^{22} \mathrm{Na}$ and ${ }^{36} \mathrm{Cl}$ as previously described $(14,15)$. The net fluxes of $\mathrm{Na}$ and $\mathrm{Cl}$ were calculated as the difference between the two unidirectional fluxes $\left(\mathrm{Ji}\right.$ net $=\mathrm{Ji}_{\mathrm{m}-\mathrm{s}}-\mathrm{Ji}_{\mathrm{s}-\mathrm{m}}$ ). A $\mathrm{Ji}$ net different from 0 represents active transport of ion. The $\mathrm{Jr}$ net, calculated as Isc-( $\mathrm{JNa}$ net $+\mathrm{JCl}$ net $)$, is assumed to represent $\mathrm{HCO}_{3}{ }^{-}$secretion $(14,15)$.

Cyclic nucleotide measurements. These determinations were performed as described by Harper and Brooker (16). Briefly, three pieces of intestinal mucosa were placed in 25-mL Erlenmeyer flasks containing $3 \mathrm{~mL}$ of Ringer's solution and gassed with $5 \% \mathrm{CO}_{2}$. After $20 \mathrm{~min}$ of equilibration at $37^{\circ} \mathrm{C}$ in a water bath, toxin was added, and after $1 \mathrm{~min}$ the pieces were removed and immediately placed in 5\% ice-cold trichloroacetic acid containing $4 \mathrm{nCi}$ of $\left[{ }^{3} \mathrm{H}\right] \mathrm{cAMP}$ or $\left[{ }^{3} \mathrm{H}\right] \mathrm{cGMP}$. Tissues were homogenized and centrifuged at $3000 \times g$ for $15 \mathrm{~min}$. The supernatants were taken and trichloroacetic acid was extracted four times with aqueous diethyl ether 1:9 (vol:vol) and evaporated to dryness at $70^{\circ} \mathrm{C}$ in a water bath.
The dried residues were redissolved in $0.6 \mathrm{~mL}$ of $100-\mathrm{mM}$ sodium acetate buffer, $\mathrm{pH} 6.2$, and cAMP or cGMP, determined by a RIA, as previously described (15). Results are expressed as pmol of cyclic nucleotide/mg protein. Statistical analysis was performed by the $t$ test. $\left[{ }^{3} \mathrm{H}\right] \mathrm{cGMP},\left[{ }^{3} \mathrm{H}\right] \mathrm{cAMP},{ }^{22} \mathrm{NaCl}$ and $\mathrm{Na}^{36} \mathrm{Cl}$ were purchased from Amersham (Buckinghamshire, England). Lyophilized cAMP and cGMP antibodies were obtained from Beckton-Dickinson (Orangeburg, NY). MAb 20C1B8 were a generous gift of Dr R. Giannella (Cincinnati, $\mathrm{OH}$ ). All chemicals were of reagent grade.

\section{RESULTS}

Twenty-six strains of Klebsiella ( $15 \mathrm{~K}$. pneumoniae, $11 \mathrm{Kleb}$ siella oxytoca) were isolated from the 237 patients (11\%), and 36 strains (22 K. pneumoniae, $14 \mathrm{~K}$. oxytoca) were isolated from the 179 controls $(20 \%)$. Two strains of $K$. pneumoniae, both isolated from patients, showed positivity in the SMA

Case reports. An infant $45 \mathrm{~d}$ of age was admitted to our Unit because of acute-onset, watery diarrhea. The patient had severe dehydration and metabolic acidosis and required intravenous administration of a glucose saline solution. Fecal excretion was $65 \mathrm{~mL} / \mathrm{kg} / \mathrm{d}$; fecal osmolality was $280 \mathrm{mo} / \mathrm{sm} / \mathrm{L}$, fecal Na and $\mathrm{K}$ were 46 and $75 \mathrm{mEq} / \mathrm{L}$, respectively and the osmolal gap was 36. Stool examination resulted in the isolation of a SMA-positive $K$. pneumoniae strain (API code 5254773). No other enteric pathogens were detected. The patient received chlorpromazine, which was successful in reducing the fecal output to a vol $25 \%$ that at admission. She was discharged after $15 \mathrm{~d}$ in good general condition.

The other patient harboring an SMA-positive $K$. pneumoniae strain was a 16-mo old female. Clinical and laboratory features were similar to the case reported above. The overall clinical picture was slightly milder, probably because the patient was older.

Enterotoxic activity. Culture supernatant of $K$. pneumoniae strain AL55 showed a positive result in the SMA with a GW/ $\mathrm{BW}$ ratio of 0.165 . The positive control $(E$. coli $214 \mathrm{Cl})$ had a ratio of 0.131

The UM-2 retentate, lyophilized and redissolved in water to a concentration of $10 \mathrm{mg}$ protein $/ \mathrm{mL}$ had a $\mathrm{GW} / \mathrm{BW}$ ratio of 0.113 . The negative control was $<0.080$. In the same set of experiments, the UM-2 ultrafiltrate gave a GW/BW ratio of 0.100 . Maximal ST activity of the gel filtration fractions was associated with the void vol. These fractions were pooled, lyophilized, and stored at $-20^{\circ} \mathrm{C}$ until further use.

Major physicochemical characteristics. These were all determined using the SMA. The characteristics of Klebsiella enterotoxin are listed in Table 1, together with those of $E$. coli and $C$. freundii ST for comparison. The biologic activity of $K$. pneumoniae enterotoxin was not affected by heating at $60^{\circ} \mathrm{C}$ for 60 min or $100^{\circ} \mathrm{C}$ for $10 \mathrm{~min}$, as indicated by the positivity of the

Table 1. Physicochemical, biologic, and immunologic characteristics of $K$. pneumoniae enterotoxin in comparison with $E$. coli and C. freundii $S T a$

\begin{tabular}{lccc}
\hline & K. pneumoniae & C. freundii & E. coli \\
\hline Mol wt & $2000-10000$ & 2000 & 1972 \\
Heat-stability & + & + & + \\
$\mathrm{pH}$ inactivation & $>8$ & $>8$ & $>8$ \\
2-mercaptoethanol & + & + & + \\
Inactivation & & + & + \\
Methanol-solubility & + & $3-4$ & $2-4$ \\
Peak of activity & 3 & - & - \\
In the SMA (h) & & & + \\
Activity in 18 h & - & & + \\
Rabbit ileal loop assay & & & \\
Reactivity with & - & & \\
Anti-E. coli antibodies & & &
\end{tabular}


SMA. Maximal activity was found at a $\mathrm{pH}$ range of 5-7. Enterotoxic activity disappeared at $\mathrm{pH}$ values $>8$. Enterotoxic activity was present only in the methanol-soluble fraction. Chemical reduction with 2-mercaptoethanol or dithiothreitol abolished the biologic activity of $K$. pneumoniae enterotoxin.

Biologic activity. The time course of secretion induced by culture supernatant of $K$. pneumoniae is shown in Figure $1 . K$. pneumoniae ST had a rapid effect, similar to E. coli ST. Compared to $E$. coli $\mathrm{ST}$, it was hypertoxigenic, as shown by the very briefer duration than that of $E$. coli ST. $K$. pneumoniae toxin was inactive in the $18 \mathrm{~h}$ rabbit ileal loop assay for heat-labile enterotoxin detection.

Interaction with anti-E. coli ST MAb. Culture supernatants of enterotoxic $K$. pneumoniae did not react with anti- $E$. coli ST $\mathrm{MAb}$, whereas $E$. coli $214 \mathrm{C} 1$ and $C$. freundii ST-positive culture supernatants were positive.

Effects on short circuit current and on net transepithelial fluxes of $\mathrm{Na}$ and $\mathrm{Cl}$. The addition of increasing doses of fractions from the void vol of the Sephadex G-25 column to the mucosal side of rabbit ileal mucosa, mounted in Ussing chambers, resulted in a dose-dependent increase of Isc (Fig. 2). This response was

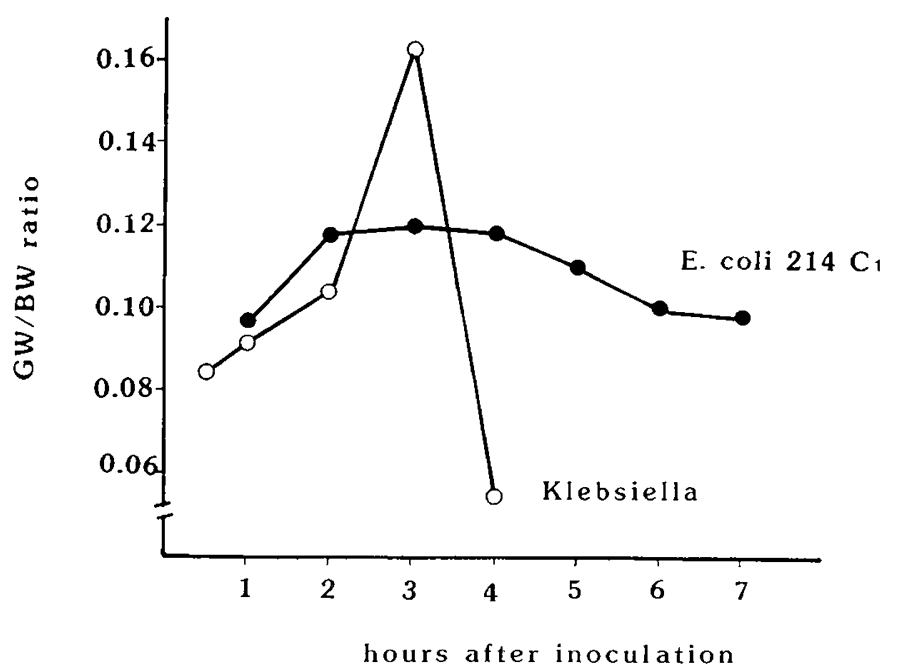

Fig. 1. Time course of enterotoxic activity of $K$. pneumoniae ST and of $E$. coli $214 \mathrm{Cl} \mathrm{ST}$. The culture supernatants of $K$. pneumoniae and of E. coli $214 \mathrm{Cl}(0.1 \mathrm{~mL})$ were injected into a mouse. The animals were killed at various times, and the $\mathrm{GW} / \mathrm{BW}$ ratio was determined. A GW/ $\mathrm{BW}$ ratio greater than 0.083 was considered positive. Each point represents the mean of three separate experiments.

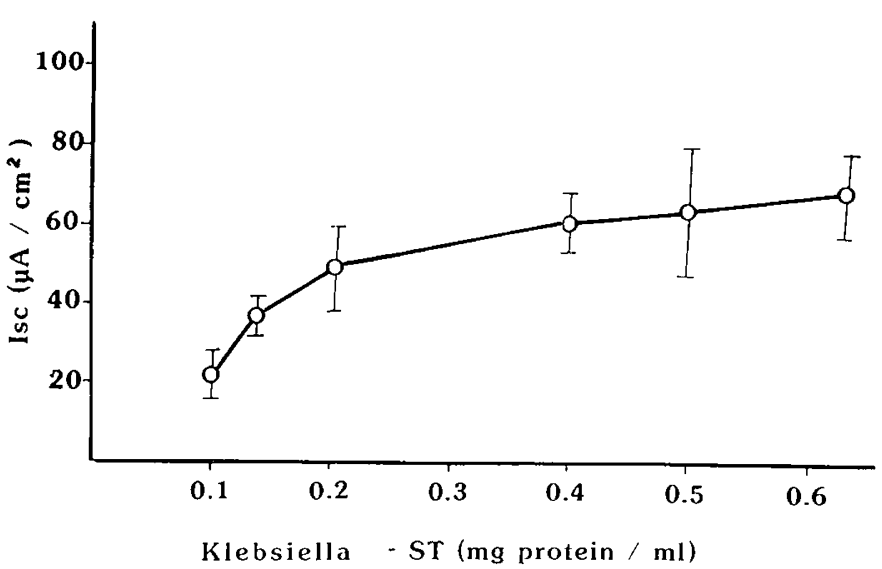

Fig. 2. Effect of Klebsiella ST on short circuit current $(I S c)$ in rabbit ileal mucosa mounted in Ussing chambers. The mucosal addition of increasing concentrations of Klebsiella ST induced a rapid dose-dependent increase in Isc. Results are means \pm SEM of four different experiments. extremely rapid, starting within a few seconds after the addition of the toxin, and showed a slow trend to saturation. In further experiments, we have used our preparation at the concentration of $0.4 \mathrm{mg} / \mathrm{mL}$ of this enterotoxin preparation. This concentration was chosen because it induced an almost maximal increase of Isc of about $60 \mu \mathrm{AMP} / \mathrm{cm}^{2}$.

To investigate the effects of $K$. pneumoniae enterotoxin on ion transport, we have measured transepithelial bidirectional steady state fluxes of $\mathrm{Na}$ and $\mathrm{Cl}$ across short circuited ileal mucosa before (period 1) and $10 \mathrm{~min}$ after (period 2) mucosal addition of $0.4 \mathrm{mg} / \mathrm{mL}$ of the enterotoxin preparation. Results are given in Fig. 3. Klebsiella ST addition resulted in an inhibition of $\mathrm{Na}$ and $\mathrm{Cl}$ unidirectional $\mathrm{m}$-s flux of the same magnitude (about 2 $\mu \mathrm{Eq} / \mathrm{cm}^{2} \cdot \mathrm{h}$ ), with a concomitant increase in $\mathrm{Cl}$ unidirectional sm flux of approximately $1.5 \mu \mathrm{Eq} / \mathrm{cm}^{2} \cdot \mathrm{h}$. Such alterations result in significant changes in the corresponding ion net fluxes: $\mathrm{Na}$ net transport is abolished and $\mathrm{Cl}$ net absorption is reversed to secretion after the toxin addition. Such changes are similar, both qualitatively and quantitatively, to those seen after the addition of $E$. coli ST (6).

Effects on intracellular concentration of CAMP and CGMP (Fig. 4). K. pneumoniae enterotoxin induced a prompt increase in cGMP concentration from $0.63 \pm 0.08 \mathrm{pmol} / \mathrm{mg}$ protein in the controls to $1.41 \pm 0.33$ and to $1.62 \pm 0.15 \mathrm{pmol} / \mathrm{mg}$ protein upon the addition of 2 and $10 \mathrm{mg} / \mathrm{mL}$ of the toxin, respectively $(p<0.05)$. There were no differences between the concentrations of cAMP under control conditions and after the addition of partially purified toxin at the concentration of $2 \mathrm{mg} / \mathrm{mL}$ and 10 $\mathrm{mg} / \mathrm{mL}$.

\section{DISCUSSION}

E. coli $\mathrm{ST}$ are classified into two groups, STa and STb, on the basis of physicochemical and biologic characteristics (17). STa has been purified and sequenced, and is clearly pathogenic for man; less is presently known about STb.

Bacteria other than $E$. coli, such as $C$. freundii (18), Yersinia enterocolitica (19), and Vibrio cholerae non-01 (20) have also been shown to produce STa-like enterotoxins with segments of amino acid sequences identical to those of $E$. coli $\mathrm{STa}$.

It is now clear that STa is $\therefore$ family of small peptides, whose amino acid sequence is peculiar in that it has six cysteine residues forming three disulfide bridges. The bridges act to stabilize the tertiary structure, are responsible for the physicochemical characteristics of the molecules, and are required for biologic activity (21). Different ST have a highly homologous core, which includes the six cysteine residues, but may contain some differences in the amino acid sequence.

Strains of $K$. pneumoniae producing enterotoxins have been occasionally reported $(22,23)$. Klipstein and Engert (8) described an enterotoxin produced by $K$. pneumoniae, which was heatstable and active when perfused in the rat jejunum. The estimated mol wt of the partially purified toxin was 5000 . Subsequently, Klipstein et al. (9) purified a K. pneumoniae ST using the same procedure developed to purify $E$. coli ST. They found that this toxin showed immunologic cross-reactivity to $E$. coli $S T$ and was equipotent to $E$. coli ST in the SMA (9). The investigators stated that the relationship between the two $K$. pneumoniae toxins described by them was unknown (9).

We have isolated two ST-producing $K$. pneumoniae strains from two children with acute diarrhea. In the cases described, the clinical and laboratory features, namely the fecal osmolal gap, were consistent with a secretory diarrhea (24). The beneficial response to chlorpromazine, a potent antisecretory drug, further supports this assumption. The physicochemical and biologic characteristics of $K$. pneumoniae ST closely resemble those of $E$. coli STa (17). In fact $K$. pneumoniae ST is heat-stable, methanolsoluble, mercaptoethanol-sensitive, active in the SMA, but inactive in the 18-h ileal loop assay. The $\mathrm{pH}$ pattern is also similar to that described for STa toxins $(25,26)$. Furthermore, the 


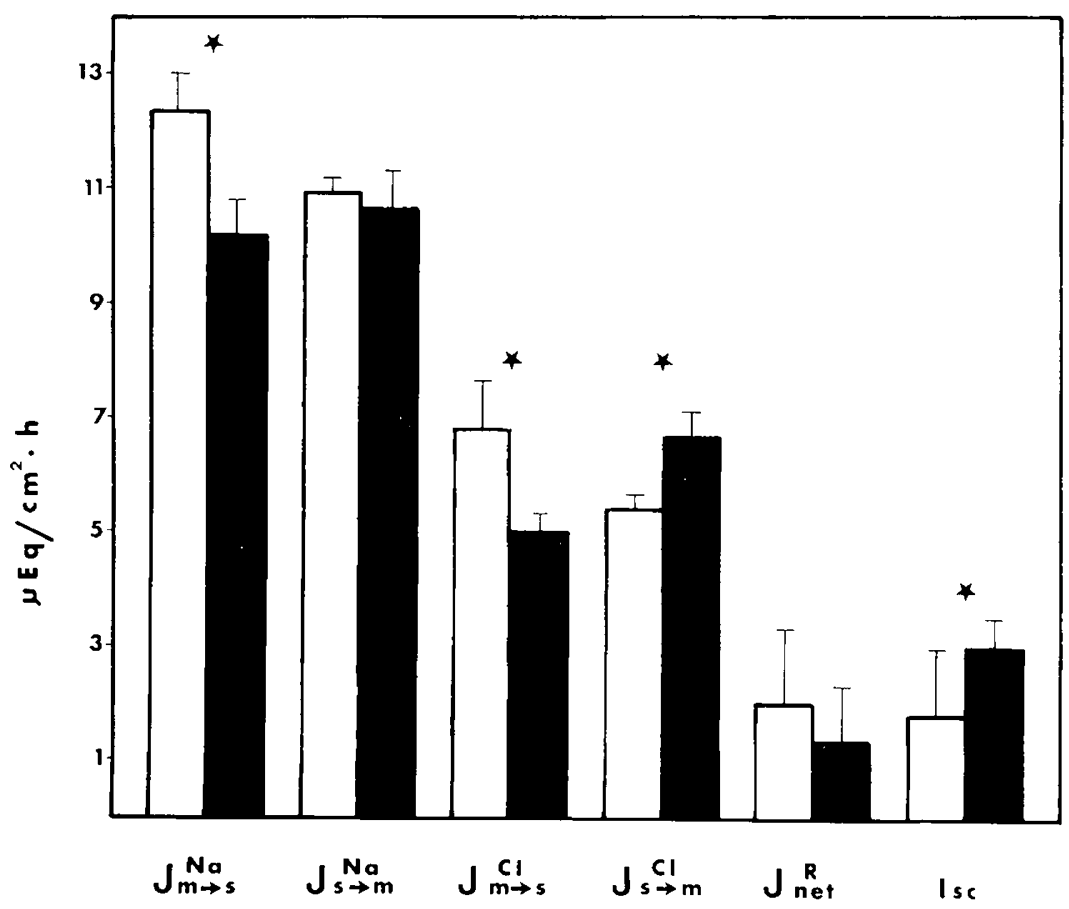

Fig. 3. Effect of Klebsiella ST on unidirectional transepithelial electrolyte fluxes in rabbit ileal mucosa mounted in Ussing chambers. Open bars refer to period 1, baseline fluxes; closed bars to period 2, fluxes measured in the same tissues after addition of the toxin $(0.4 \mathrm{mg} / \mathrm{mL})$ to the mucosal side. Values represent means \pm SEM for five rabbits. $\star$, statistically significant $(p<0.05)$ changes.

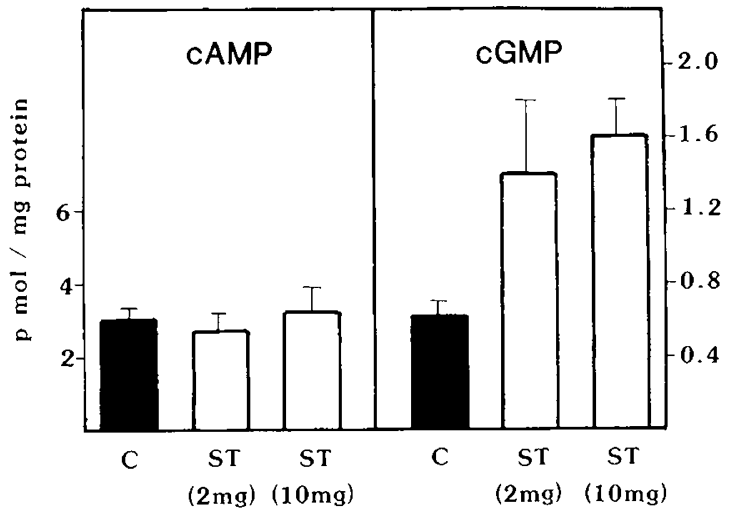

Fig. 4. Effect of Klebsiella ST (2 and $10 \mathrm{mg}$ ) on cAMP and cGMP concentrations in rabbit ileal mucosa. Results are means \pm SEM of four different animals.

estimated mol wt is in the range of that reported for similarly prepared E. coli STa (20).

Interestingly, the time course of the $K$. pneumoniae ST-induced effect was markedly different from that of $E$. coli STa, i.e. being more potent and of shorter duration. Another clear difference with $E$. coli STa is the absence of reactivity of Klebsiella ST with specific anti-E. coli STa MAb. This suggests a difference in the amino acid sequence, at least in the epitope recognized by the antibody used. Klipstein et al. reported an immunologic relationship between their $K$. pneumoniae ST and E. coli STa (9). This apparent conflicting finding can result either from differences in the antibodies used or from differences in the amino acid sequences of the ST produced by the two K. pneumoniae strains.

Even though differences in the sequence might be real, the mechanism of action of $K$. pneumoniae ST is identical to that of $E$. coli $\mathrm{ST}$, as proven by the effects on Isc, ion fluxes, and on cyclic nucleotides. The effects on Isc are in every way similar to that described for $E$. coli ST, being prompt, dose-dependent, with only a partial trend toward saturation (5). K. pneumoniae
ST affects electrolyte transport both by reducing $\mathrm{Na}$ absorption and inducing a net $\mathrm{Cl}$ secretion. The latter is quantitatively the major effect. Residual ion flux, representing bicarbonate transport, was not significantly altered.

Just as for $E$. coli ST (6), the effects on electrolyte transport of $K$. pneumoniae ST are related to the induced increase in cGMP, whereas no effect was observed on cAMP. The effect of $E$. coli ST on cGMP has been recently studied in a human-derived colonic cell line and has been shown to be coupled to the binding of the toxin to receptors located on the luminal side of the intestinal mucosa (27). We can therefore assume that $K$. pneumoniae ST exerts its effects through the identical multistep mechanism of action of E. coli STa.

In conclusion: $K$. pneumoniae may induce diarrhea by the production of an ST; this ST is an STa on the basis of its physicochemical and biologic characteristics. The mechanism of action is the same as of $E$. coli STa. Its amino acid sequence may be different from $E$. coli $\mathrm{STa}$, as suggested by the lack of cross-reactivity with the MAb to E. coli STa.

\section{REFERENCES}

1. Black RE, Brown KH, Becker S, Alim AR, Huq I 1982 Longitudinal studies of infectious diseases and physical growth in rural Bangladesh. II. Incidence of diarrhea and association with known pathogens. Am J Epidemiol 15:315324

2. Guarino A, Alessio M, Tarallo L, Fontana M, Iacono G, Gobio Casali L, Guandalini S 1989 E. coli heat-stable enterotoxin in acute diarrhoea. Arch Dis Child (in press)

3. Giannella RA, Luttrell M, Thompson MR 1983 Binding of E. coli heat-stable enterotoxin to receptors on rat intestinal cells. Am J Physiol 245:G492G498

4. Guarino A, Cohen MB, Overmann G, Thompson MR, Giannella RA 1987 Binding of $E$. coli heat-stable enterotoxin to rat intestinal brush borders and to basolateral membranes. Dig Dis Sci 32:1017-1026

5. Field M, Graf LH, Laird WJ, Smith PL 1978 Heat-stable enterotoxin of $E$. coli: in vitro effects on guanylate cyclase activity, cyclic GMP concentration, and ion trasnport in small intestine. Proc Natl Acad Sci USA 75:2800-2804

6. Guandalini S, Rao MC, Smith P, Field M 1982 cGMP modulation of ileal ion transport: in vitro effects of Escherichia coli heat stable enterotoxin. Am J Physiol 243:G36-G41

7. Guarino A, Capano G, Malamisura B, Alessio M, Guandalini S, Rubino A 1987 Production of Escherichia coli STa-like enterotoxin by Citrobacter freundii isolated from humans. J Clin Microbiol 25:110 114

8. Klipstein FA, Engert RF 1976 Purification and properties of Klebsiella pneu- 
moniae heat-stable enterotoxin. Infect Immun 3:373-38

9. Klipstein FA. Engert RF, Houghten RA 1983 Immunological properties of Klebsiella pneumoniae heat-stable enterotoxin. Infect Immun 42:838-841

10. Giannella RA 1976 Suckling mouse model for detection of heat-stable Esche richia coli enterotoxin: characteristics of the model. Infect Immun 14:95-99

11. Lowry OH, Rosebrough NH, Farr AL, Randall RJ 1951 Protein measuremen by Folin phenol reagent. J Biol Chem 193:265-275

12. Thompson MR, Brandwein H, Labine-Racke M, Giannella RA 1984 Simple and reliable enzyme-linked immunosorbent assay with monoclonal antibodies for detection of Escherichia coli heat-stable enterotoxins. J Clin Microbio 20:59-64

13. Brandwein H, Deutsch A, Thompson M, Giannella RA 1985 Production of neutralizing monoclonal antibodies to Escherichia coli heat-stable enterotoxin. Infect Immun 47:242-246

14. Field M, Fromm D, McColl I 1971 Ion transport in rabbit ileal mucosa. I. Na and $\mathrm{Cl}$ fluxes and short circuit current. Am J Physiol 220:1388-1396

15. Guandalini S, Kachnur JF, Smith PL, Miller RJ, Field M 1980 In vitro effects of somatostatin on ion transport in rabbit intestine. Am J Physiol 238:G67G74

16. Harper JF, Brooker G 1975 Femtomole sensitive radioimmunoassay for cyclic AMP and cyclic GMP after $2^{\prime} 0$ acetylation by acetic anhydride in aqueous solution. J Cyclic Nucleotide Res 1:207-218

17. Burgess MN, Bywater RJ, Cowley CM, Mullan NA, Newsome PM 1978 Biological evluation of a methanol-soluble heat-stable Escherichia coli en terotoxin in infant mice, pigs, rabbits and calves. Infect Immun 21:526-531

18. Guarino A, Giannella R, Thompson MR 1989 Citrobacter freundii produce an 18-amino-acid enterotoxin identical to the 18-amino acid Escherichia coli heat-stable enterotoxin (ST 1A). Infect Immun 57:649-652
19. Takao T, Tominaga N, Shimonishi Y 1984 Primary structure of heat-stable enterotoxin produced by Yersinia enterocolitica. Biochem Biophys Res Commun 125:845-851

20. Honda T, Arita M, Takeda T, Yoh M, Miwatani T 1985 Non-01 Vibrio cholerae produces two newly identified toxins related to Vibrio parahemolyticus hemolysin and Escherichia coli heat-stable enterotoxin. Lancet 2. 163-164

21. Thompson MR 1987 Escherichia coli heat-stable enterotoxins and their receptors. Pathol Immunopathol Res 6:103-116

22. Stintzing G, Mollby R, Habte D 1982 Enterotoxigenic Escherichia coli and other enteropathogens in paediatric diarrhoea in Addis Ababa. Acta Paediatr Scand 71:279-286

23. Guerrant RL, Kirchhoff LV, Shieids DS, Nations MK, Leslie J, de Sousa MA, Araujo JG, Correia LL, Sauer KT, McClelland KE, Trowbridge FL, Hughes JM 1983 Prospective study of diarrheal illnesses in Northeastern Brazil: patterns of disease, nutritional impact, etiologies and risk factors. $J$ Infect Dis 148:986-997

24. Krejs GJ, Fordtran JS 1983 Diarrhea. In: Sleisinger MH, Fordtran JS(eds) Gastrointestinal Disease, 3rd ed. WB Saunders, Philadelphia, pp 258-280

25. Staples SJ, Asher SE, Giannella RA 1980 Purification and characterization of heat-stable enterotoxin produced by a strain of $E$. coli pathogenic for man. J Biol Chem 255:4716-4721

26. Mitchell IG, Tame MJ, Kenworthy M 1984 Separation and purification of enterotoxins from a strain of Escherichia coli pathogenic for pigs. J Med Microbiol 7:439-450

27. Guarino A, Cohen M, Thompson M, Dharmasathaphorn K, Giannella RA 1987 T84 cell receptor binding and guanylate cyclase activation by Escherichia coli heat-stable toxin. Am J Physiol 16:G775-G780 